\title{
Tomographic Reconstruction of Microstructures in Al-Ni-Y-Based Alloys
}

\author{
M.A. Gordillo, ${ }^{*}$ L.C. Zhang, ${ }^{*}$ T.J. Watson, ${ }^{* *}$ M. Aindow*
}

* Department of Chemical, Materials and Biomolecular Engineering, Institute of Materials Science, University of Connecticut, Storrs, Connecticut 06269

** Pratt and Whitney, East Hartford, Connecticut 06108

The development of low-density high-strength aerospace alloys offers significant advantages in terms of improved fuel efficiency and/or engine performance. For many airframe applications, conventional precipitation-hardened $\mathrm{Al}$ alloys are the materials of choice because they offer an attractive combination of properties including: low density, low cost and good formability. The strengths that can be achieved in $\mathrm{Al}$ alloys are, however, limited by the maximum volume fractions of the precipitate phase(s), which in turn depend on the solubility limits for the alloying elements.

In our work we have been studying the use of metastable Al-based vitreous intermediates to overcome the solubility limits for crystalline Al. Controlled devitrification of such metallic glasses gives microstructures with significantly higher volume fractions of precipitates than can be obtained in conventional Al Alloys with corresponding increases in strength (e.g. [1]). The main emphasis of this work has been on the Al-Ni-Y system in which metastable glasses can be obtained for a range of compositions at modest cooling rates. The main precipitate phase that forms upon devitrification is $\mathrm{Al}_{19} \mathrm{Ni}_{5} \mathrm{Y}_{3}$, with $\mathrm{Al}_{3} \mathrm{Ni}$ or $\mathrm{Al}_{3} \mathrm{Y}$ as a minority phase [2]. The $\mathrm{Al}_{19} \mathrm{Ni}_{5} \mathrm{Y}_{3}$ exhibits a plate morphology and this inhibits coarsening of the Al grains. Since the plates are typically larger than the grains of the Al matrix, composite effects will dominate the strengthening, not Orowan looping [3]. Thus, the orientations of the plates will be a significant factor in determining the mechanical behavior.

In this paper we report a study on an $\mathrm{Al}-13 \mathrm{Y}-11 \mathrm{Ni}-1 \mathrm{Co}$ alloy processed by gas atomization to give amorphous powder, followed by canning and extrusion to give a fully consolidated alloy: previous studies have shown that devitrification occurs during consolidation due to adiabatic heating effects. The extruded alloys were then sectioned and upset forged parallel to the extrusion direction. FIBbased serial section tomography was then used to evaluate the morphology, distribution and orientation of the plates in as-extruded material and in forgings with upsets of $43 \%, 64 \%$ and $84 \%$. Serial sectioning was performed using a FEI Dual Beam Strata 400S system by: depositing a Pt strap onto the polished sample surface; FIB milling a $3 \mu \mathrm{m}$ deep U-shaped trench around the strap to give a $2 \times 3 \times 3 \mu \mathrm{m}$ "pier" as the volume of interest; FIB cleaning the pier faces using a low beam current; and then obtaining a series of 200 secondary electron SEM images from the pier face, FIB polishing a slice of about $15 \mathrm{~nm}$ in thickness from the face between each image. The image stacks were then reconstructed to reveal the morphology and orientations of the plates. Typical examples of SEM images and reconstructions are shown in Figure 1. These data reveal that the plates are initially aligned parallel to the extrusion direction and that they rotate during forging: at $84 \%$ upset they lie perpendicular to the extrusion/forging axis. The rotation is not accompanied by significant fracture or refinement of the plates. Thus, the devitrified alloy acts as a plastically deformable composite.

References

[1] AL Vasiliev, M Aindow, MJ Blackburn and TJ Watson, Intermetallics 12: 349-362 (2004).

[2] AL Vasiliev, M Aindow, MJ Blackburn and TJ Watson, Scripta Mater 52: 699-704 (2005).

[3] NJ Magdefrau, AL Vasiliev, M Aindow et al., Scripta Mater 51: 485-489 (2004). 
a

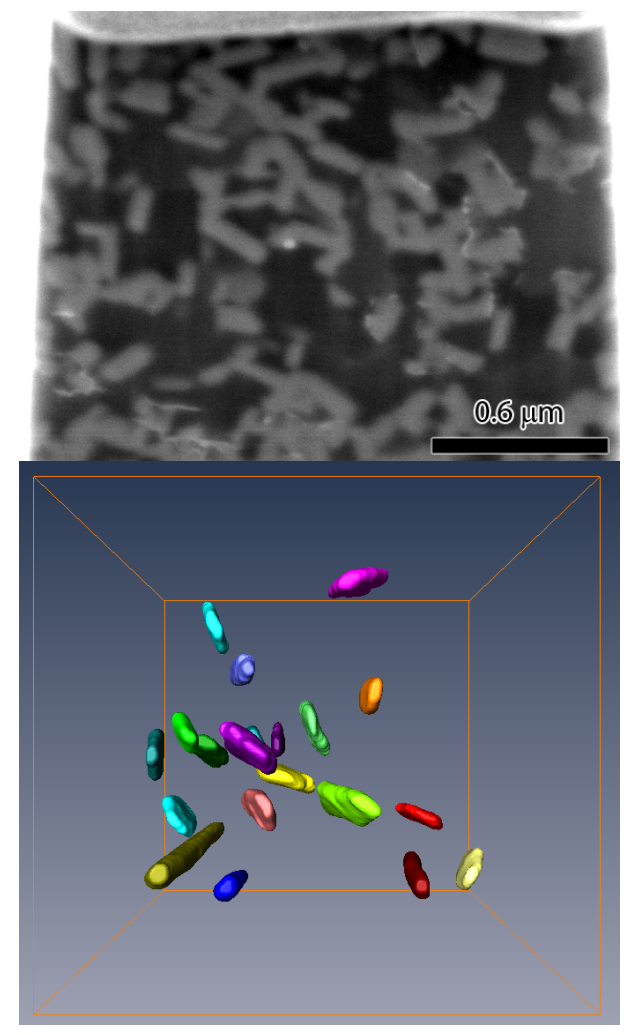

C

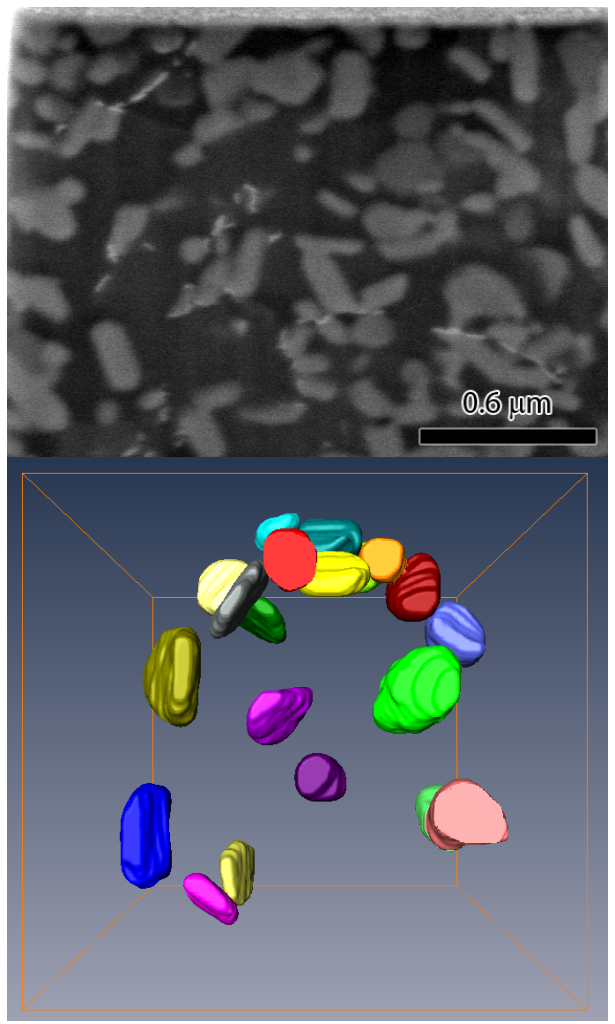

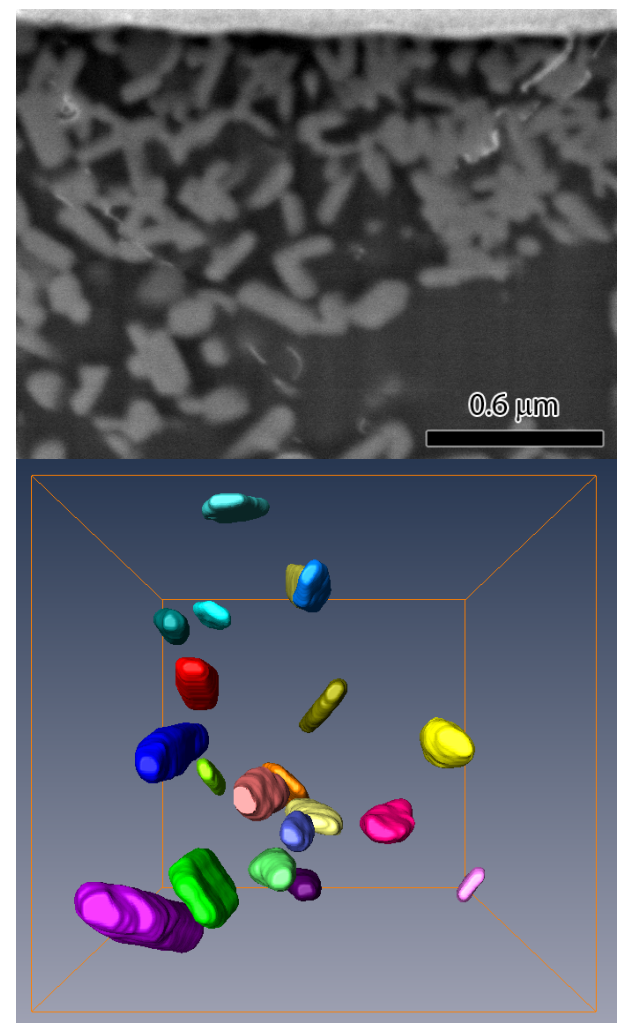

$\mathrm{b}$

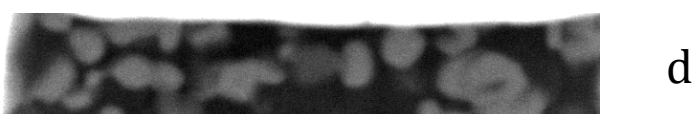

$\mathrm{d}$

Figure 1: Distribution of $\mathrm{Al}_{19} \mathrm{Ni}_{5} \mathrm{Y}_{3}$ plates in the devitrified alloy after forging upsets of: (a) $0 \%$, (b) $43 \%$, (c) $64 \%$, and (d) $84 \%$. The upper figure is an SEM image taken from the face of the FIB-cut pier, and the lower is a $2 \times 2 \mu \mathrm{m}$ tomographic reconstruction showing orientations of selected plates. 